Article

\title{
Integrin $\alpha v \beta 6$ as a Target for Tumor-Specific Imaging of Vulvar Squamous Cell Carcinoma and Adjacent Premalignant Lesions
}

\author{
Bertine W. Huisman ${ }^{1,2}{ }^{\oplus}$, Merve Cankat ${ }^{1,2}$, Tjalling Bosse ${ }^{3}$, Alexander L. Vahrmeijer ${ }^{4}$, Robert Rissmann ${ }^{1,5}$, \\ Jacobus Burggraaf ${ }^{1,4,5}$, Cornelis F. M. Sier ${ }^{4,6, *,+}$ ) and Mariette I. E. van Poelgeest ${ }^{1,2, \dagger}$ \\ 1 Center for Human Drug Research, 2333 CL Leiden, The Netherlands; bhuisman@chdr.nl (B.W.H.); \\ mcankat@chdr.nl (M.C.); rrissmann@chdr.nl (R.R.); kb@chdr.nl (J.B.); m.i.e.van_poelgeest@lumc.nl (M.I.E.v.P.) \\ 2 Department of Gynecology, Leiden University Medical Center, 2333 ZA Leiden, The Netherlands \\ 3 Department of Pathology, Leiden University Medical Center, 2333 ZA Leiden, The Netherlands; \\ t.bosse@lumc.nl \\ 4 Department of Surgery, Leiden University Medical Center, 2333 ZA Leiden, The Netherlands; \\ a.l.vahrmeijer@lumc.nl \\ 5 Leiden Academic Center for Drug Research, Leiden University, 2333 CC Leiden, The Netherlands \\ 6 Percuros BV, 2333 CL Leiden, The Netherlands \\ * Correspondence: c.f.m.sier@lumc.nl \\ + These authors share co-senior authorship.
}

\section{check for} updates

Citation: Huisman, B.W.; Cankat, M.; Bosse, T.; Vahrmeijer, A.L.; Rissmann,

R.; Burggraaf, J.; Sier, C.F.M.; van

Poelgeest, M.I.E. Integrin $\alpha v \beta 6$ as a Target for Tumor-Specific Imaging of Vulvar Squamous Cell Carcinoma and Adjacent Premalignant Lesions. Cancers 2021, 13, 6006. https:// doi.org/10.3390/cancers13236006

Academic Editors: Mario Preti and Denis Querleu

Received: 27 October 2021

Accepted: 25 November 2021

Published: 29 November 2021

Publisher's Note: MDPI stays neutral with regard to jurisdictional claims in published maps and institutional affiliations.

Copyright: (c) 2021 by the authors. Licensee MDPI, Basel, Switzerland. This article is an open access article distributed under the terms and conditions of the Creative Commons Attribution (CC BY) license (https:// creativecommons.org/licenses/by/ $4.0 /)$.
Simple Summary: Vulvar tumors are sometimes difficult to distinguish from adjacent healthy tissue during surgery, causing recurrence rates of up to $40 \%$ and co-morbidity. Fluorescence-guided surgery illuminating neoplastic tissue is increasingly being used to assist surgeons for various types of cancers. As no suitable tracers are known yet for vulvar tumors, we have evaluated which proteins could be targeted for fluorescence-guided surgery. Immunohistochemistry was used to study the distribution of nine membrane proteins in healthy and (pre)malignant tissues that were consequently analyzed using quantitative image analysis. Integrin $\alpha \mathrm{v} \beta 6$ allowed for the most robust discrimination of VSCCs and adjacent premalignant lesions compared with surrounding healthy tissue. The use of an $\alpha \mathrm{v} \beta 6$ targeted near-infrared fluorescent probe for FGS of vulvar (pre)malignancies should be evaluated in future studies.

Abstract: Surgical removal of vulvar squamous cell carcinoma (VSCC) is associated with significant morbidity and high recurrence rates. This is at least partially related to the limited visual ability to distinguish (pre)malignant from normal vulvar tissue. Illumination of neoplastic tissue based on fluorescent tracers, known as fluorescence-guided surgery (FGS), could help resect involved tissue and decrease ancillary mutilation. To evaluate potential targets for FGS in VSCC, immunohistochemistry was performed on paraffin-embedded premalignant (high grade squamous intraepithelial lesion and differentiated vulvar intraepithelial neoplasia) and VSCC (human papillomavirus (HPV)-dependent and -independent) tissue sections with healthy vulvar skin as controls. Sections were stained for integrin $\alpha v \beta 6$, CAIX, CD44v6, EGFR, EpCAM, FR $\alpha$, MRP1, MUC1 and uPAR. The expression of each marker was quantified using digital image analysis. H-scores were calculated and percentages positive cells, expression pattern, and biomarker localization were assessed. In addition, tumor-tobackground ratios were established, which were highest for (pre)malignant vulvar tissues stained for integrin $\alpha \mathrm{v} \beta 6$. In conclusion, integrin $\alpha \mathrm{v} \beta 6$ allowed for the most robust discrimination of VSCCs and adjacent premalignant lesions compared to surrounding healthy tissue in immunohistochemically stained tissue sections. The use of an $\alpha \mathrm{v} \beta 6$ targeted near-infrared fluorescent probe for FGS of vulvar (pre)malignancies should be evaluated in future studies.

Keywords: vulva; squamous carcinoma; HSIL; dVIN; fluorescence-guided surgery; integrin $\alpha v \beta 6$ 


\section{Introduction}

Vulvar squamous cell carcinoma (VSCC) is a rare type of cancer with an incidence of 1.5-2.7 per 100,000 women, necessitating specialized centralized care [1]. Overall incidence worldwide is increasing. For the Dutch population, this increase is mainly observed in younger women [2,3]. There are two major pathways for the development of VSCC. Human papilloma virus (HPV)-dependent VSCC $(20 \%)$ are caused by high-risk HPV types, predominantly HPV16. HPV-dependent VSCC arises in the background of precursor lesions named high grade squamous intraepithelial neoplasia (HSIL). Another precursor of VSCC is differentiated vulvar intraepithelial neoplasia (dVIN), which often arises in elderly women with lichen sclerosus (LS), a chronic inflammatory skin disease. For dVIN, the cumulative risk of malignant progression to VSCC is estimated to be as high as $50 \%$ after 10 years and this type of VSCC has a poor survival compared to HPV-dependent VSCC [1,4-6]. The cornerstone of treatment for VSCC consists of surgery with or without radiochemotherapy $[7,8]$. Even in early-stage disease, the recurrence rate is up to $40 \%$ after 10 years, requiring repeated local surgery or (re)irradiation [9].

In more than half of the VSCC patients, surgery in the vulvar area, in particular when the tumor is located near the urethra, clitoris, or anus, is associated with significant morbidity, including disfigurement, sexual dysfunction, and psychological problems [10]. These morbidities are partly caused by the limited ability to distinguish between healthy and (pre)malignant tissue during surgery. The recognition and excision of vulvar lesions relies on the gynecologist's visual and tactile skills, experience, and information obtained from histological biopsies. Recognition by the gynecologist is even harder when the vulvar architecture is complicated by deformation associated with inflammation, atrophy, or previous treatments $[2,11]$. Positive surgical margins are associated with higher risk for local recurrence and poor survival $[12,13]$. In addition, precursor lesions are often found adjacent to the tumor, which are sometimes difficult to identify clinically and therefore not treated adequately. Consequently, better identification and timely recognition of vulvar (pre)malignant lesions may result in prevention of re-excisions, local recurrences, metastases, and associated prognosis. Real time visualization during fluorescence-guided surgery (FGS) could aid in resolving this problem.

FGS is a promising technique for real-time detection of occult tumor lesions and localization of cancer margins. The procedure makes use of a cell-specific targeting agent, linked to a near-infrared fluorescent (NIRF) dye or radiolabel, which can be visualized in real time by an advanced imaging system. Clinical studies on various cancer types have shown that FGS improves the recognition of tumor tissue significantly, primarily in cases with incomplete visual and tactile information [14,15]. Proper identification of tumor-specific targets for molecular imaging is key to the success of FGS [16]. In the last decade, FGS targets have been explored for cancer types including ovarian, colorectal, and head-and-neck cancer [17-21]. Until now, potential targets for FGS in VSCC have not been studied.

The aim of this study was to examine the expression of previously identified VSCCspecific membrane-associated targets based on the available literature and candidate targets for other squamous cancers in dVIN, HSIL, and VSCC tissues. To determine their suitability as a target for tumor-specific imaging in vulvar (pre)malignancies. The markers assessed are integrin alphavbeta6 ( $\alpha \mathrm{v} \beta 6)$, carbonic anhydrase IX (CAIX), CD44 variant 6 (CD44v6), epidermal growth factor receptor (EGFR), epithelial cell adhesion molecule (EpCAM), folate receptor $\alpha(\mathrm{FR} \alpha)$, multidrug resistance-associated protein (MRP1), mucin 1 (MUC1), and urokinase plasminogen activator receptor (uPAR) [17,18,20,22-24].

\section{Materials and Methods}

\subsection{Tissue Samples}

Pretreatment VSCC samples and precursor lesions, i.e., dVIN and HSIL (without information on treatment status) were collected from the pathology department of Leiden University Medical Center. Sample selection was based on original diagnosis described in the pathology report and the size of the available tissues. Non-squamous vulvar cancers 
were excluded. Formalin fixed paraffin embedded (FFPE) HPV-negative vulvar tissue from healthy anonymized women who underwent labia reduction surgery was included as control. Sample collection was approved by the local ethics review board (Medische Ethische Toetsingscommissie Leiden Den Haag Delft-reference number B19.025). All routinely made hematoxylin-eosin-(H\&E), p16-(overexpressed in dysplastic tissue related to HPV infection; HSIL and HPV-dependent VSCC tissues) and p53-stained slides were reviewed by an expert gynecologic pathologist (TB) blinded to immunohistochemical results and lesions diagnosed and delineated [25-28]. Intentionally, fifteen samples were collected of each vulvar tissue type/group, i.e., healthy, dVIN, HPV-independent VSCC, HSIL and HPV-dependent VSCC. Some samples were excluded because the original diagnosis of a tissue could not be confirmed or (pre)malignant cells were no longer present in the tissue sample.

\subsection{Immunohistochemistry}

FFPE tissue blocks were sectioned into tissue sections of $4 \mu \mathrm{m}$. Sections were deparaffinized in xylene and rehydrated via serially diluted ethanol solutions. Endogenous peroxide was blocked for $20 \mathrm{~min}$ with $0.3 \%$ hydrogen peroxide diluted in demineralized water. Appropriate antigen retrieval was performed depending on the antibody (Table S1). Subsequently, sections were incubated overnight at room temperature (RT) with the primary antibodies. The optimal dilution for each of the antibodies was determined beforehand on vulvar normal and/or squamous cell carcinoma test tissue. Slides were washed three times with phosphate-buffered saline (PBS, $\mathrm{pH}$ 7.5) before 30 min incubation at RT with the appropriate secondary antibody, followed by another washing step. Staining was visualized with 3,3-diaminobenzidine tetrahydrochloride solution (DAB, K3468, Agilent Technologies, Inc., Santa Clara, CA, USA) for approximately $5 \mathrm{~min}$ at RT and counterstained for $20 \mathrm{~s}$ with hematoxylin (4085.9002, VWR International, Amsterdam, The Netherlands). After dehydration, the slides were mounted with Pertex (0081EX, Histolab, Askim, Sweden). Control staining's were performed (Table 1 and Figure S1).

Table 1. Antibodies used for immunohistochemical analysis, including source, clone, stock, dilutions, antigen retrieval applied and source of control tissue per biomarker tested.

\begin{tabular}{|c|c|c|c|c|c|c|c|}
\hline Biomarker & Source & $\begin{array}{l}\text { Clone } \\
\text { Number }\end{array}$ & $\begin{array}{l}\text { Catalogue } \\
\text { Number }\end{array}$ & Stock & Dilution & Antigen Retrieval & $\begin{array}{l}\text { Positive } \\
\text { Control }\end{array}$ \\
\hline$\alpha v \beta 6$ & $\begin{array}{c}\text { Biogen, Inc., } \\
\text { Cambridge, MA, USA }\end{array}$ & $6.2 \mathrm{~A} 1$ & 62A1CEO2 & $50 \mu \mathrm{g} / \mathrm{mL}$ & $1 / 100$ & $\begin{array}{l}0.4 \% \text { pepsin (S3002 Agilent) } \\
37^{\circ} \mathrm{C} \text { for } 15 \mathrm{~min} .\end{array}$ & Normal colon \\
\hline CA IX & $\begin{array}{l}\text { Santa Cruz Biotechnology, } \\
\text { Inc., Danvers, MA, USA }\end{array}$ & $\mathrm{H}-11$ & Sc-365900 & $200 \mu \mathrm{g} / \mathrm{mL}$ & $1 / 2500$ & $\begin{array}{l}\text { Target retrieval solution, } \\
\text { pH } 6.1 \text { (K8005 Agilent) }\end{array}$ & $\begin{array}{l}\text { Normal } \\
\text { stomach }\end{array}$ \\
\hline CD44v6 & Abcam, Cambridge, UK & VFF7 & ab30436 & $1 \mathrm{mg} / \mathrm{mL}$ & $1 / 3200$ & $\begin{array}{l}\text { Target retrieval solution, } \\
\text { pH } 6.1 \text { (K8005 Agilent) }\end{array}$ & Normal skin \\
\hline EGFR & Dako, Glostrup, Denmark & E30 & M7239 & $286 \mu \mathrm{g} / \mathrm{mL}$ & $1 / 600$ & $\begin{array}{l}0.4 \% \text { pepsin (S3002 Agilent) } \\
37^{\circ} \mathrm{C} \text { for } 10 \mathrm{~min} .\end{array}$ & $\begin{array}{l}\text { Normal } \\
\text { placenta }\end{array}$ \\
\hline EpCAM & $\begin{array}{l}\text { LUMC, department } \\
\text { of pathology }{ }^{1}\end{array}$ & $323 / \mathrm{A} 3$ & - & $0.4 \mathrm{mg} / \mathrm{mL}$ & $1 / 1600$ & $\begin{array}{l}0.1 \% \text { trypsin (T7409 Sigma } \\
\text { Aldrich) } 37^{\circ} \mathrm{C} \text { for } 30 \mathrm{~min} .\end{array}$ & Colon tumor \\
\hline $\mathrm{FR} \alpha$ & $\begin{array}{l}\text { BioCare Medical, } \\
\text { Pacheco, CA, USA }\end{array}$ & 26B3.F2 & $\begin{array}{l}\text { BRI 4006K } \\
\text { AA (kit) }\end{array}$ & Assay kit & N.A. & Ready-to-use & Lung tumor \\
\hline MRP1 & $\begin{array}{l}\text { Santa Cruz Biotechnology, } \\
\text { Inc., Danvers, MA, USA }\end{array}$ & QCRL-1 & Sc-18835 & $200 \mu \mathrm{g} / \mathrm{mL}$ & $1 / 400$ & $\begin{array}{l}\text { Target retrieval solution, } \\
\text { pH 6.1 (K8005 Agilent) }\end{array}$ & $\begin{array}{l}\text { Normal } \\
\text { placenta }\end{array}$ \\
\hline MUC1 & $\begin{array}{c}\text { Invitrogen, } \\
\text { Waltham, MA, USA }\end{array}$ & E29 & $\begin{array}{l}\text { MA5- } \\
14077\end{array}$ & $0.2 \mathrm{mg} / \mathrm{mL}$ & $1 / 4800$ & $\begin{array}{l}\text { Target retrieval solution, } \\
\text { pH } 9.0 \text { (K8004 Agilent) }\end{array}$ & Normal colon \\
\hline uPAR & Monopar $^{2}$ & ATN617 & - & $0.48 \mathrm{mg} / \mathrm{mL}$ & $1 / 200$ & $\begin{array}{l}\text { Target retrieval solution, } \\
\text { pH } 6.1 \text { (K8005 Agilent) }\end{array}$ & Colon tumor \\
\hline p16 & $\begin{array}{l}\text { Roche, } \\
\text { Almere, The Netherlands }\end{array}$ & E6H4 & 06695248001 & $\begin{array}{l}\text { Ready-to- } \\
\text { use }\end{array}$ & $1 / 25$ & TRIS/EDTA & Normal cervix \\
\hline p53 & $\begin{array}{c}\text { DAKO, } \\
\text { Santa Clara, CA, USA }\end{array}$ & DO-7 & GA61661-2 & Ready to use & $1 / 2000$ & TRIS/EDTA & Normal cervix \\
\hline
\end{tabular}

${ }^{1}$. Kindly provided by Jaap van Eendenburg, department of pathology LUMC, The Netherlands. ${ }^{2}$. Kindly provided by Andrew Mazar, Monopar Therapeutics Inc., Wilmette, IL, USA. 


\subsection{Digital Pathology Image Analysis}

Stained sections were digitalized with a Panoramic Digital Slide Scanner (3D Histech, Budapest, Hungary), stored as tiled tiff format, and imported into QuPath (version 2.0.0). QuPath is an open-source software tool for digital pathology image analysis [29-31]. Based on delineation of tissues by pathologist TB, tumor and premalignant borders were manually annotated in Qupath by $\mathrm{BH}$ and $\mathrm{MC}$ and copied to sequential sections. Within all these tissue annotations, cell detection, cell classification and staining quantification was conducted by a script (Script S1). After running the script, an export file of the results was automatically generated in MS excel. This export file included intensity thresholds for positive stained cells, divided in three categories: low (1+), medium (2+) or high (3+) intensity staining (examples of by QuPath processed image are shown in Figures S2 and S3).

\subsection{Marker Staining}

Based on the number of positive cells and their intensity, Qupath automatically generated $\mathrm{H}$-scores by the formula ' $1 \times(\%$ cells threshold $1+)+2 \times(\%$ cells threshold $2+)+3 \times(\% \text { cells threshold } 3+)^{\prime}$ for all annotations. H-scores range from 0 to 300 , giving more relative weight to higher-intensity staining in a tissue section. The following $\mathrm{H}$-score categories were defined: 0-50 low, 50-250 medium and 250-300 high marker staining [32]. Median, minimum and maximum H-scores per vulvar tissue type were calculated. In addition, tumor-to-background ratios (TBRs) were calculated by dividing the median $\mathrm{H}$-score of vulvar (pre)malignant tissue by the median $\mathrm{H}$-score for healthy vulvar tissue.

\subsection{FGS Criteria}

A potential protein marker for FGS based on IHC-staining was defined by fulfillment of all the following criteria [16,22,33]:

i. a median $\mathrm{H}$-score in (pre)malignant tissue being at least twice as high as the median $\mathrm{H}$-score in healthy control and stromal tissue [34];

ii. a minimum median $\mathrm{H}$-score in (pre)malignant tissue of at least 25;

iii. homogeneous expression throughout the tumor;

iv. cell surface protein expression.

\subsection{Statistics}

Median, minimum, and maximum $\mathrm{H}$-scores were extracted from Qupath and TBRs calculated (Table 2). To test for favorable TBRs, a statistical analysis was performed on the comparison of median $\mathrm{H}$-scores per vulvar tissue types (healthy vulva (HV)/dVIN, HV/HPVindependent VSCC, HV/HSIL, HV/HPV-dependent VSCC, dVIN/HPV-independent VSCC, HSIL/HPV-dependent VSCC) using a Mann-Whitney U test. Statistical analyses were performed using Graphpad Prism version 9.1.0 for MacOS (Graphpad Prism Software, San Diego, CA, USA). These results were presented in boxplots with 1st and 3rd quartiles. Several tissue sections contained different tissue type annotations located at one section. Only H-scores of annotations of the predefined tissue type of a patient were included in this analysis. Annotations located near the predefined tissue type annotation (e.g., VSCC patient with adjacent healthy tissue) were not included. As the data were not expected to be normally distributed, a Mann-Whitney U test was used to test for statistical significance of difference in group medians. No adjustment was considered for multiple testing issues due to the exploratory nature of this study. Thus, hypothesis testing results with $p<0.05$ were considered statistically significant. For marker(s) that showed potential as FGS target based on the selection criteria (Section 2.5), a spaghetti plot was generated for data visualization. The lines in this plot represent patients, the dots are average H-scores per vulvar tissue type within a VSCC patients tissue section. This plot was completed for both HPV-dependent and -independent VSCC patients. No statistical analysis was performed; these data were used for visualization of $\mathrm{H}$-scores and corresponding TBRs per patient. 
Table 2. Median, minimum (min), maximum (max) H-scores and tumor-to-background ratios (TBRs) for each marker per vulvar tissue group are presented. TBRs $>2$ are displayed in green (IGS criterion 1, Section 2.5) and a minimum median H-scores of at least 25 in blue (IGS criterion 2, Section 2.5). HPV- VSCC = HPV-independent VSCC and $\mathrm{HPV}+\mathrm{VSCC}=\mathrm{HPV}$-dependent VSCC.

\begin{tabular}{|c|c|c|c|c|c|c|c|c|c|c|c|c|}
\hline & \multicolumn{4}{|c|}{$\alpha v \beta 6$} & \multicolumn{4}{|c|}{ CAIX } & \multicolumn{4}{|c|}{ CD44v6 } \\
\hline & Median & Min & Max & TBR & Median & Min & Max & TBR & Median & Min & Max & TBR \\
\hline Healthy $(n=15)$ & 9 & 2 & 31 & - & 2 & 0 & 19 & - & 240 & 173 & 283 & - \\
\hline $\operatorname{dVIN}(n=10)$ & $59^{b}$ & 20 & 216 & 6.6 & $7^{b}$ & 1 & 65 & 3.5 & 248 & 123 & 275 & 1.0 \\
\hline HPV - VSCC $(n=16)$ & 118 & 0 & 231 & 13.1 & $9^{a}$ & 1 & 77 & 4.5 & 196 & 96 & 271 & 0.8 \\
\hline HSIL $(n=15)$ & $42^{b}$ & 3 & 145 & 4.7 & 5 & 1 & 92 & 2.5 & 223 & 119 & 279 & 0.9 \\
\hline \multirow[t]{3}{*}{$\mathrm{HPV}+\operatorname{VSCC}(n=13)$} & 93 & 7 & 213 & 10.3 & 6 & 1 & 102 & 3.0 & $118^{a}$ & 51 & 267 & 0.5 \\
\hline & \multicolumn{4}{|c|}{ EGFR } & \multicolumn{4}{|c|}{ EpCAM } & \multicolumn{4}{|c|}{$\mathrm{FR} \alpha$} \\
\hline & Median & Min & Max & TBR & Median & Min & Max & TBR & Median & Min & Max & TBR \\
\hline Healthy $(n=15)$ & 61 & 2 & 200 & - & 2 & 0 & 12 & - & 3 & 1 & 43 & - \\
\hline $\operatorname{dVIN}(n=10)$ & 40 & 2 & 138 & 0.7 & 5 & 0 & 11 & 2.5 & 1 & 1 & 3 & 0.3 \\
\hline HPV $-\operatorname{VSCC}(n=16)$ & 129 & 4 & 253 & 2.2 & 3 & 0 & 17 & 1.5 & $4^{a}$ & 2 & 7 & 1.3 \\
\hline HSIL $(n=15)$ & 10 & 0 & 213 & 0.2 & 2 & 0 & 17 & 1.0 & 2 & 0 & 28 & 0.7 \\
\hline \multirow[t]{3}{*}{$\mathrm{HPV}+\operatorname{VSCC}(n=13)$} & 25 & 5 & 106 & 0.4 & $7^{a}$ & 0 & 91 & 3.5 & 4 & 2 & 60 & 0.3 \\
\hline & \multicolumn{4}{|c|}{ MRP1 } & \multicolumn{4}{|c|}{ MUC1 } & \multicolumn{4}{|c|}{ uPAR } \\
\hline & Median & Min & Max & TBR & Median & Min & Max & TBR & Median & Min & $\operatorname{Max}$ & TBR \\
\hline Healthy $(n=15)$ & 4 & 0 & 29 & - & 11 & 1 & 81 & - & 6 & 1 & 22 & - \\
\hline dVIN $(n=10)$ & 8 & 0 & 24 & 2.0 & 63 & 20 & 206 & 5.7 & $12^{b}$ & 2 & 35 & 2.0 \\
\hline HPV - VSCC $(n=16)$ & $13^{c}$ & 0 & 42 & 0.3 & $34^{a}$ & 3 & 184 & 3.1 & $37^{c}$ & 5 & 91 & 6.2 \\
\hline HSIL $(n=15)$ & 2 & 0 & 22 & 0.5 & 40 & 3 & 201 & 3.6 & $6^{c}$ & 0 & 73 & 1.0 \\
\hline HPV + VSCC $(n=13)$ & 2 & 0 & 17 & 0.5 & 62 & 14 & 176 & 5.6 & $19^{a}$ & 1 & 125 & 3.1 \\
\hline
\end{tabular}

\section{Results}

\subsection{Tissue Characteristics}

In total, 10 dVIN, 16 HPV-independent VSCC, 15 HSIL, 13 HPV-dependent VSCC tissues and 15 healthy vulvar controls were included for biomarker expression evaluation. Due to incidental poor slide quality, not all selected tissue samples could be scored for each marker.

\subsection{Immunohistochemical Marker Staining}

Hereafter, a narrative description of the staining of each marker will be given categorized by the previously mentioned four FGS criteria (Section 2.5). Markers are listed in alphabetic order.

\subsection{1. $\alpha \mathrm{v} \beta 6$-Integrin Alphavbeta6}

i. Stromal tissue lacked $\alpha v \beta 6$ expression. Healthy vulvar epithelium showed no or low expression of $\alpha \mathrm{v} \beta 6$. If $\alpha \mathrm{v} \beta 6$ was present in healthy vulvar tissue, it was mainly located in the spinosal and basal layer of the epithelium (Figure 1A). In addition, $\alpha \mathrm{v} \beta 6$ expression was higher in normal vulvar tissues wherein sebaceous glands were present (11/15 healthy vulvar tissues) compared with vulvar tissue sections that lacked those glands. $\alpha \mathrm{v} \beta 6$ staining within sebaceous glands was low to moderate (Figure 1A). The median H-score of healthy vulvar tissue was significantly lower compared with median H-scores of all vulvar (pre)malignant tissue types (Figure 2), resulting in TBRs $>2$ (Table 2). 


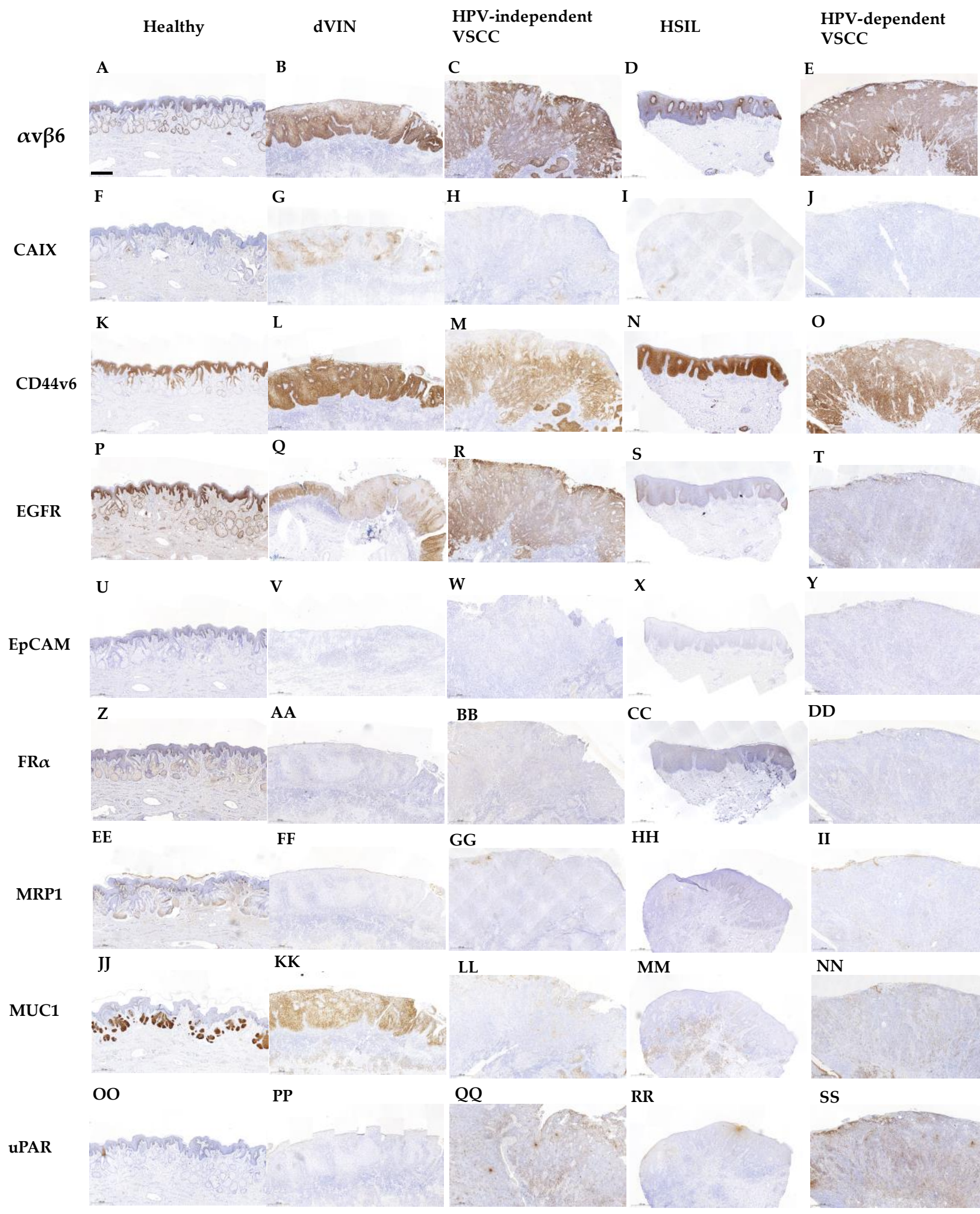

Figure 1. Representative images of $\alpha \mathrm{v} \beta 6$ (A-E), CAIX (F-J), CD44v6 (K-O), EGFR (P-T), EpCAM (U-Y), FR $\alpha$ (Z-DD), MRP1 (EE-II), MUC1 (JJ-NN) and uPAR (OO-SS) expression in healthy vulvar tissue with (sebaceous) glands, differentiated vulvar intraepithelial neoplasia (dVIN), human papilloma virus-independent vulvar squamous cell carcinoma (HPVindependent VSCC), high grade squamous intraepithelial lesion (HSIL) and human papilloma virus-dependent vulvar squamous cell carcinoma (HPV-dependent VSCC). All images show only the predefined tissue type of that section (no adjacent tissue). Scale bars represent $500 \mu \mathrm{m}$. 


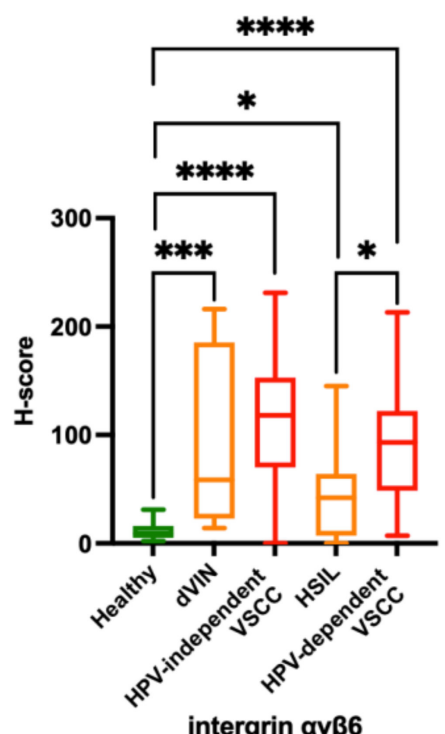

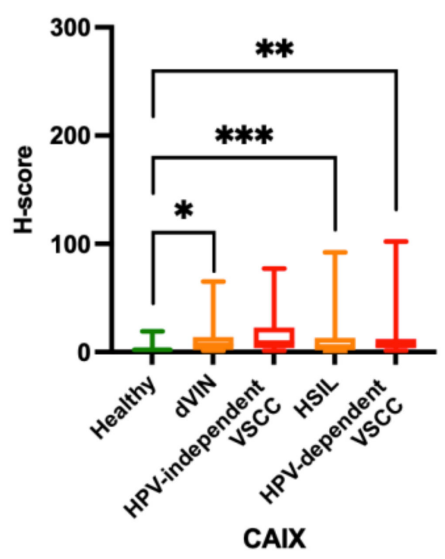

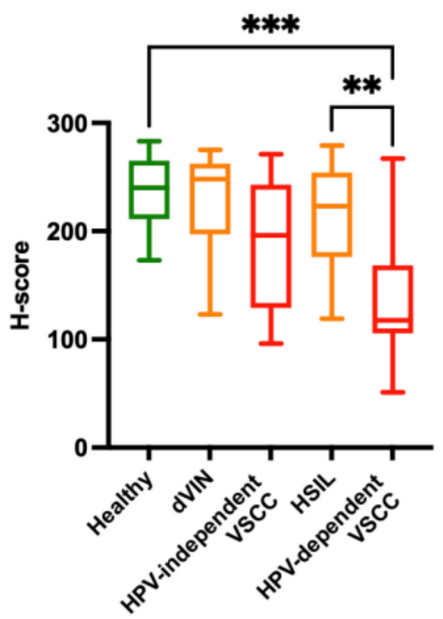

CD44v6

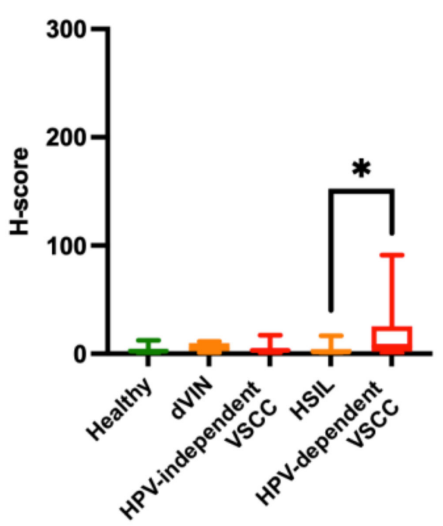

EPCAM

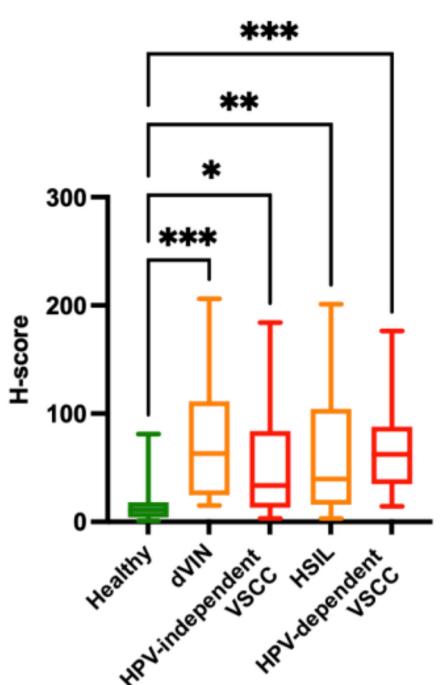

MUC1

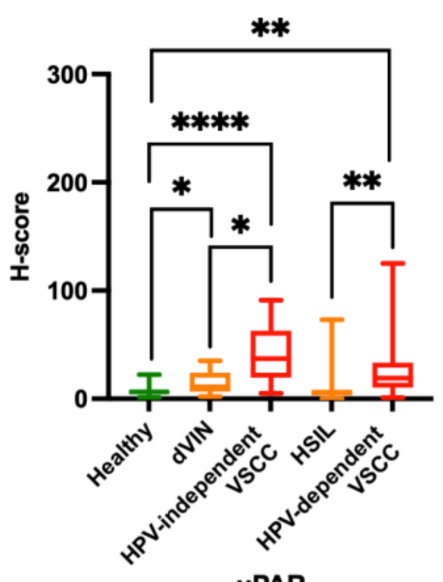

uPAR

Figure 2. Boxplots representing median $H$-scores per vulvar tissue type (including 1st and 3rd percentiles) for integrin $\alpha v \beta 6$, CAIX, CD44v6, EGFR, EpCAM, FR $\alpha$, MRP1, MUC1, uPAR. Statistical analyses were performed between different median Hscores: HV/dVIN, HV/HPV-independent VSCC, HV/HSIL, HV/HPV-dependent VSCC, dVIN/HPV-independent VSCC, HSIL/HPV-dependent VSCC. ns $=p>0.05$ (not shown), ${ }^{*}=p \leq 0.05,{ }^{* *}=p \leq 0.01,{ }^{* * *}=p \leq 0.001,{ }^{* * * *}=p \leq 0.0001 .10 \mathrm{dVIN}$, 16 HPV-independent VSCC, 15 HSIL, 13 HPV-dependent VSCC tissues and 15 healthy vulvar controls were included. 
ii. Moderate $\alpha \mathrm{v} \beta 6$ expression was observed in 4/8 dVIN, 14/16 HPV-independent VSCC, 4/13 HSIL and 10/13 HPV-dependent VSCC tissues (Figure 1B-E respectively). $\alpha \mathrm{v} \beta 6$ expression lacked in 2/16 HPV-independent VSCC and 3/13 HPV-dependent VSCC tissues. The other premalignant tissues showed low expression. More intense $\alpha v \beta 6$ staining was found in HSIL adjacent to HPV-dependent VSCC (average H-score 42) compared with isolated HSIL (average $\mathrm{H}$-score 114). This difference was not observed for dVIN. Median H-scores per vulvar (pre)malignant tissues type were all above 25 (Table 2).

iii. $\alpha v \beta 6$ was homogeneously expressed in all HPV-independent VSCC tissues. 2/10 HPV-dependent VSCC tissues showed a patchy staining pattern throughout the tumor, for 2/10 expression was restricted to the spinosal and/or basal layers, the remainder showed homogeneous expression. To a greater or lesser extent in all dVIN and HSIL tissues, as for healthy vulvar tissue, $\alpha \mathrm{v} \beta 6$ expression was restricted to the spinosal and/or basal layers (Figure 1A,D).

iv. $\quad \alpha v \beta 6$ showed cell membrane staining.

\subsubsection{CAIX-Carbonic Anhydrase IX}

i. Stromal and healthy vulvar epithelium lacked CAIX staining (Figure 1F). The median $\mathrm{H}$-score of healthy vulvar tissues was significantly lower compared with median $\mathrm{H}$-scores of dVIN, HSIL and HPV-dependent VSCC tissue groups (Figure 2), resulting in TBRs > 2 (Table 2). The median H-score of HPV-independent VSCC tissue group was not tested significantly higher compared with the median H-score of healthy vulvar tissue (TBR 4.5, Table 2).

ii. Most vulvar (pre)malignant tissues showed low CAIX expression (Figure $1 \mathrm{H}-\mathrm{J}$ ), 1-2 samples per tissue group showed moderate CAIX expression (Figure 1G). Median $\mathrm{H}$-scores per vulvar (pre)malignant tissues type were all below 25 (Table 2).

iii. If CAIX staining was observed, it was positioned in the spinosal and/or basal layers of the vulvar epidermis in a heterogeneous and patchy pattern (Figure 1G-J).

iv. CAIX showed cell membrane staining.

\subsubsection{CD44v6-CD44 Variant 6}

i. Stromal tissue lacked CD44v6 staining. Healthy vulvar epithelium showed in $7 / 15$ tissues high CD44v6 expression, the remaining tissues showed moderate expression (Figure 1K). TBRs were inverse for all (pre)malignant vulvar tissue types, indicating downregulation of CD44v6 in (pre)malignant compared with healthy tissue (Figure 2). Consequently, TBRs were not in favor for FGS application at the surface of the vulva (Table 2).

ii. Predominantly moderate CD44v6 staining was observed in vulvar (pre)malignant tissues (Figure 1L-O), in 5/10 dVIN, 3/16 HPV-independent VSCC, 5/15 HSIL and 1/12 HPV-dependent VSCC tissues high CD44v6 expression was observed. Median CD44v6 H-scores per vulvar (pre)malignant tissues type were all above 25 (Table 2).

iii. CD44v6 showed homogenous expression.

iv. CD44v6 showed cell membrane staining.

\subsubsection{EGFR—Epithelial Cell Adhesion Molecule}

i. EGFR staining was observed in glands, blood vessels and adnexa. Healthy vulvar epithelium showed moderate EGFR expression in 10/15 tissues (Figure 1P) and low expression in 5/15 tissues. TBRs were inverse for all (pre)malignant vulvar tissue types, indicating downregulation of EGFR in (pre)malignant tissue compared with healthy (Figure 2) Consequently, TBRs were not in favor for FGS application at the surface of the vulva (Table 2).

ii. EGFR was moderately expressed in 5/10 dVIN, 11/16 HPV-independent VSCC, 5/15 HSIL and 2/13 HPV-dependent VSCC tissues (Figure 1Q,R), the expression in the remaining samples was low (Figure 1S,T, except 1 HPV-independent VSCC with 
high expression). HSIL showed a median H-score below 25, the H-scores for other vulvar (pre)malignant tissue types were at least 25 (Table 2).

iii. EGFR was gradually expressed in healthy vulvar epithelium, being more strongly expressed in the stratum basal compared with the stratum corneum. For (pre)malignant tissues the expression patterns were diverse. Homogenous (Figure 1R), patchy (Figure 1Q,S) and on/off expression patterns (Figure 1T) were observed in these tissues.

iv. EGFR showed cell membrane staining.

\subsubsection{EpCAM—Epithelial Cell Adhesion Molecule}

i. EpCAM staining was not observed in stromal tissue, except for the endothelial lining of blood vessels. Healthy vulvar epithelium lacked EpCAM expression (Figure 1U). The median $\mathrm{H}$-score of healthy vulvar tissue was not significantly different compared with any vulvar (pre)malignant tissue group (Figure 2), resulting in TBRs $<2$, except for dVIN with an TBR of 2.5 (Table 2).

ii. EpCAM expression was absent or low for all vulvar (pre)malignant tissue types (Figure 1V-Y), with median H-scores below 25 (Table 2).

iii. No pattern could be recognized due to the low expression of EpCAM in vulvar tissues.

iv. EpCAM showed cell membrane staining on the endothelial lining of blood vessels.

\subsubsection{FR $\alpha$-Folate Receptor $\alpha$}

i. FR $\alpha$ staining was absent in both stromal and healthy vulvar epithelium (Figure 1Z). The median $\mathrm{H}$-score of healthy vulvar tissue was significantly lower compared with the median $\mathrm{H}$-score of dVIN tissue (Figure 2), resulting in a TBR $>2$. TBRs for other (pre)malignant tissue groups were $<2$ (Table 2).

ii. FR $\alpha$ expression was absent or low for all vulvar (pre)malignant tissue types (Figure 1AA-DD), with median $\mathrm{H}$-scores below 25 (Table 2).

iii. No pattern could be recognized due to the low expression of FR $\alpha$ in all vulvar tissues.

iv. Cell membrane staining for FR $\alpha$ was observed in lung tumor tissue (control).

\subsubsection{MRP1—Multidrug Resistance-Associated Protein}

i. Low to moderate MRP1 staining was observed in stromal cells and several sebaceous glands of a few healthy and (pre) malignant tissues. No MRP1 expression was observed in healthy vulvar epithelium (Figure 1EE). The median H-score of healthy vulvar tissue was not significantly lower compared with any median H-score of (pre)malignant tissues (Figure 2), resulting in TBRs $<2$ (Table 2).

ii. MPR1 expression was absent or low for all vulvar (pre)malignant tissue types (Figure 1FF-II), with median H-scores below 25 (Table 2).

iii. No expression pattern could be recognized due to the overall low expression of MRP1.

iv. In both stromal vulvar tissue as in placental tissue (control), cytoplasmatic and membranous presence of MRP1 was observed on cells.

\subsubsection{MUC1-Mucin 1}

i. Stromal tissue lacked MUC1 staining, except for sebaceous glands positioned in the dermis, which showed moderate or high MUC1 expression (Figure 1JJ). Half of the healthy vulvar epithelial tissues lacked MUC1 expression (Figure 1JJ), others showed low expression restricted to the stratum spinosum. The median $\mathrm{H}$-score of healthy vulvar tissue was significantly lower compared with median $\mathrm{H}$-scores of all vulvar (pre)malignant tissue types (Figure 2), resulting in TBRs $>2$ (Table 2).

ii. Moderate MUC1 expression was observed in 5/10 dVIN (Figure 1 KK), 6/16 HPVdependent VSCC, 6/14 HSIL and 7/13 HPV-dependent VSCC tissues, the remaining tissues showed low expression (Figure 1LL-NN). Median H-scores for MUC1 expression per vulvar (pre)malignant tissues type were all above 25 (Table 2).

iii. The expression pattern was heterogenous and patchy throughout all tissue samples.

iv. MUC1 showed cell membrane staining. 


\subsection{9. uPAR-Urokinase Plasminogen Activator Receptor}

i. Low stromal expression of uPAR was observed in healthy and (pre)malignant tissues. Healthy vulvar epithelium lacked uPAR staining(Figure 1OO). The median H-score of healthy vulvar tissues was significantly lower compared with median $\mathrm{H}$-scores of dVIN, HPV-dependent and independent VSCC tissue groups (Figure 2), resulting in TBRs $>2$ (Table 2). For the HSIL group, the TBR $<2$.

ii. Moderate uPAR expression was observed in 4/12 HPV-independent VSCC (Figure 1QQ), 1/12 HSIL and 2/12 HPV-dependent VSCC tissues (Figure 1SS), the remaining vulvar (pre)malignant tissues showed low or absent expression (Figure 1PP,RR). Only the median H-score for UPAR expression in the HPV-independent VSCC tissue group was above 25 (Table 2).

iii. uPAR was heterogeneously expressed throughout (pre)malignant vulvar tissue.

iv. uPAR showed cell membrane staining and sometimes cytoplasmatic staining in cells.

\subsection{Evaluation of FGS Criteria}

Based on biomarker expression in the vulvar tissue cohort (Section 3.2), only $\alpha \mathrm{v} \beta 6$ meets all four criteria required to serve as a potential target for tumor-specific imaging in vulvar (pre)malignancies. Therefore, further evaluation of biomarker expression in individual VSCC sections was performed for $\alpha \mathrm{v} \beta 6$. Representative examples of $\alpha \mathrm{v} \beta 6$ stained HPV-dependent and HPV-independent VSCC sections, processed by Qupath, are shown in Figures S2 and S3 respectively. The other biomarkers were excluded for further analysis because CAIX, EpCAM, MRP1 showed H-scores for (pre)malignant tissue below 25, TBRs for CD44v6 and EGFR appeared to be inverse and heterogeneous expression was observed for MUC1 and uPAR.

\section{4. $\alpha v \beta 6$ Expression in Individual VSCC Tissue Sections}

Evaluation of $\alpha \mathrm{v} \beta 6$ expression on an individual level was not performed for all patients, as 7/16 HPV-independent and 3/13 HPV-dependent VSCC tissue sections did not contain adjacent healthy and/or precursor tissue. In $7 / 9$ HPV-independent and 4/10 HPVdependent VSCC patients TBRs $>2$, based on H-scores of both malignant and premalignant compared with healthy, were observed (represented by a green line, Figure 3). In $3 / 10$ HPV-dependent VSCC sections only favorable TBRs for premalignant compared to healthy were observed (represented by an orange line, Figure 3). In 2/9 HPV-independent and 3/10 HPV-dependent VSCCs TBRs were not in favor of FGS at all (indicated by a red line, Figure 3). Based on this pilot, $\alpha v \beta 6$ could serve as a suitable target for tumor-specific imaging in vulvar (pre)malignancies for $78 \%$ of HPV-dependent VSCC patients (with adjacent dVIN tissue) and 40\% of HPV-dependent VSCC patients. As not all cases showed $\alpha \mathrm{v} \beta 6$ positivity, CAIX, MUC1 and UPAR TBRS were plotted against $\alpha \mathrm{v} \beta 6$ TBRs for all 19 above-mentioned VSCC patients, to check case-by-case for an alternative target in case of $\alpha v \beta 6$ negativity (Figure S4.) Those alternative targets were chosen as they showed TBRs $>2$ for a part of the VSCC patients. In a few cases MUC1 or uPAR might serve as an alternative target (left upper quadrant, Figure S4.) 


\section{H-scores and corresponding TBRs of integrin av $\beta 6$ expression in:}
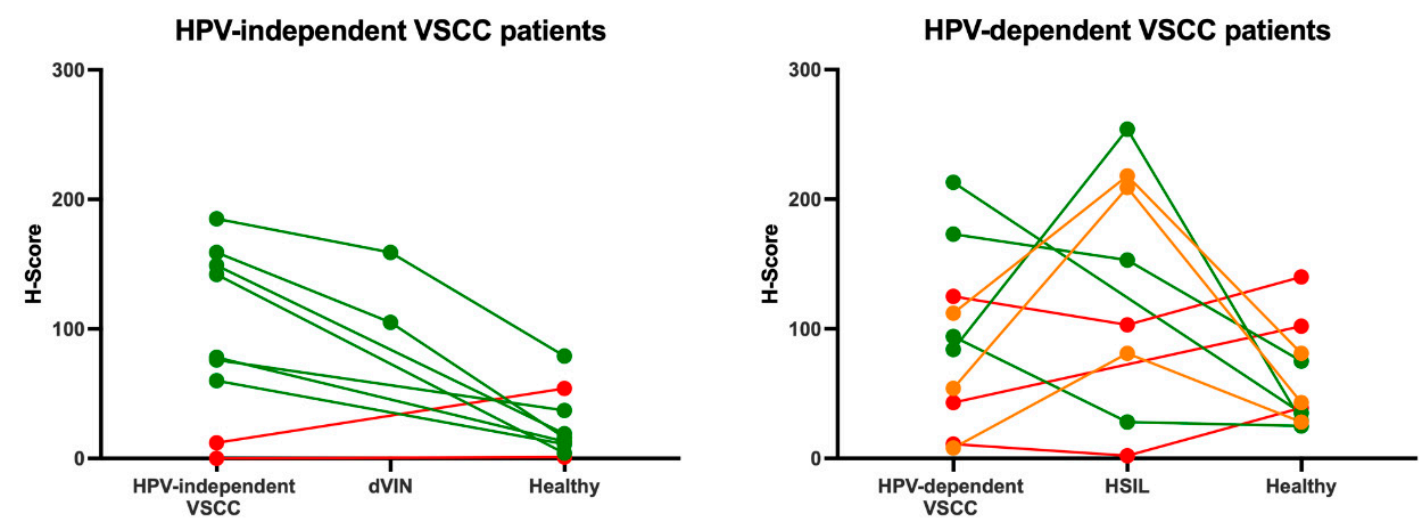

\section{$\square$ Patient with a TBR $>2$ for both VSCC and dVIN/HSIL compared to adjacent healthy tissue \\ Patient with a TBR $<2$ for VSCC and a TBR $>2$ for HSIL compared to adjacent healthy tissue \\ Patient with a TBR $\leq 2$ for VSCC and HSIL compared to adjacent healthy tissue}

Figure 3. Spaghetti plots of integrin $\alpha \mathrm{v} \beta 6$ expression within VSCC patients. Lines in this plot represent patients, a dot is an average $\mathrm{H}$-score of a vulvar tissue type within that patient's tissue section (for instance the average $\mathrm{H}$-score of all adjacent HSIL tissue annotations). Left: HPV-independent VSCC patients, right: HPV-dependent VSCC patients. Based on H-scores, TBRs are calculated (H-score (pre)malignant tissue/H-score of healthy tissue $=\mathrm{TBR})$. A green line indicates higher expression of $\alpha \mathrm{v} \beta 6$ in (pre)malignant compared to the healthy tissue (TBR $>2$ ); an orange line indicates a TBR $<2$ for VSCC and a TBR > 2 for HSIL compared to healthy tissue; a red line indicates higher expression in healthy compared to (pre)malignant tissue (TBR $\leq 1)$. Not all TBRs of VSCC patients are plotted, as not all tissue samples included normal (and/or premalignant) tissue adjacent to the tumor.

\section{Discussion}

Demarcation of vulvar (pre)malignancies during diagnosis, staging and surgery is often difficult for clinicians. This phenomenon contributes to significant morbidity and high recurrence rates of up to $40 \%$ for VSCC patients after treatment. FGS could improve resection precision of involved tissue and decrease mutilating surgeries. To our knowledge, no data have been published on the use of FGS for VSCC or precursor lesions. Therefore, we used IHC to evaluate target expressions on vulvar tissues to assess their potential for FGS. Our selection of targets was based on (i) enhanced expression in vulvar tumors as described in the available literature and (ii) effectiveness of tracers against these targets obtained from studies with other tumor types $[17,18,20,22-24]$.

Out of 9 candidates we assessed, integrin $\alpha \mathrm{v} \beta 6$ emerged as the most promising target for FGS of VSCC based on immunohistochemistry. This conclusion is based on the upregulated homogeneous expression of $\alpha \mathrm{v} \beta 6$ in VSCCs compared with surrounding stromal tissue and normal squamous epithelium of the healthy control group. Resulting in TBRs well above the set limit of 2. These suitable TBRs were confirmed within VSCC patient's using IHC. $\alpha v \beta 6$ showed suitable TBRs in $78 \%$ of HPV-independent and $40 \%$ of HPV-dependent VSCC patients (Figure 3). TBRs for $\alpha \mathrm{v} \beta 6$ in premalignancies $\mathrm{dVIN}$ and HSIL were lower compared with VSCC, but still above the indicated threshold. Higher $\alpha \mathrm{v} \beta 6$ expression was found in HSIL adjacent to HPV-dependent VSCCs compared with isolated HSIL, encouraging more effective removal of adjacent HSIL during VSCC surgery.

CAIX, EpCAM, MRP1 and FR $\alpha$ showed no or low expression in vulvar malignant tissues and were therefore excluded from further evaluation. CD44v6 and EGFR showed an overall high expression in all tissues, including normal squamous epithelium, resulting in reversed TBRs. If desired, these last two markers could help discriminate infiltrating tumor tissue with FGS, due to the absence of both markers in surrounding stromal tissue. 
Alternatively, these markers may be used for reversed fluorescence imaging, with distinctive higher expression of the target in healthy compared with malignant tissue [35]. MUC1 and UPAR were excluded from further evaluation due to their heterogenous or patchy expression pattern in vulvar malignant tissue.

Although several markers (EGFR, CD44v6, MRP1, MUC1 and CAIX) were identified as potential targets for FGS of VSCCs based on our systematic review, their candidacies were not always confirmed in this study [22]. This discordance might be explained by the absence of normal tissue as well as the choice of antibodies and different methods applied in the various IHC studies. Effects of expression patterns per antibody are for example explained in an IHC study on cervical cancer tissues [36]. Finding the antibody with the highest expression pattern in tumor tissue was not the goal of this study. Instead, we chose to apply antibodies most similar to 'corresponding' clinically available FGS in order to (i) translate the IHC results in to an imaging setting and (ii) accelerate a future clinical translation if a target/tracer combination showed potential.

Several observations should be considered when proceeding with $\alpha \mathrm{v} \beta 6$ as a target for FGS in VSCC. First, with the used integrin $\alpha \mathrm{v} \beta 6$ antibody we observed positively stained sebaceous glands just below the vulvar epithelium in the healthy control tissue. The sac-like alveoli of sebaceous glands are composed of stratified cuboidal or polyhedral epithelial cells. We noticed more sebaceous glands positioned in epithelium of the control vulvar tissues compared with adjacent normal tissue in VSCC samples. The healthy control tissue was obtained from younger women. Sebaceous gland activity is known to decrease in women after menopause, which might be advantageous for TBR-ratios in elderly vulvar cancer patients $[37,38]$. Whether the remaining positively stained $\alpha v \beta 6$ glands lead to difficulties during FGS in younger patients is hard to predict. We assume that the fluorescent signal of these glands will be inferior to the superficial and more enhanced expression in tumors. Another observation that should be considered when proceeding with $\alpha v \beta 6$ as target, is the fact that not all VSCC samples showed enhanced $\alpha \mathrm{v} \beta 6$ expression. Minimal or absent $\alpha \mathrm{v} \beta 6$ expression was noted in two HPV-independent and two HPV-dependent VSCC samples, resulting in $14 \%$ of VSCC cases. In comparison with other squamous tumor, this "on/off" phenomenon was seen in 13\% cutaneous squamous cell carcinoma patients [20]. For the $\alpha v \beta 6$-negative cases, we assessed if other examined targets could be used instead. Not one of the other examined markers met all four FGS criteria (Section 2.5) and could generally be used for $\alpha v \beta 6$-negative cases. However, a case-by-case evaluation should be performed for personalized alternatives in case of $\alpha \mathrm{v} \beta 6$-negativity. In some cases, MUC1 or UPAR might serve as an alternative VSCC-target for FGS in case of $\alpha \mathrm{v} \beta 6$ negativity (Figure S4, left upper quadrant).

An explanation for the different expression patterns of integrin $\alpha \mathrm{v} \beta 6$ in VSCC remains elusive. A hallmark function of $\alpha \mathrm{v} \beta 6$ is the activation of transforming growth factor- $\beta 1$ (TGF-1) to modulate innate immune surveillance in e.g., skin. Therefore, it is possible that different expression patterns of $\alpha \mathrm{v} \beta 6$ are explained by the difference in tumor-immune infiltration [38]. In addition, different FIGO stages of included tumors may explain variation in expression patterns. High-grade progressive tumors show different levels of cell-adhesion compared with low-grade tumors and integrins are cell surface receptors responsible for cell-to-matrix and cell-to-cell adhesion [38-40]. Structural differences in expression patterns, especially those observed between the virally and non-virally induced tumors, should be confirmed in larger cohort studies. The availability of patients' medical history including FIGO stage, detailed demographics, surgical margins, and other characteristics could improve the value of the data set substantially. Especially the assessment of whether $\alpha \mathrm{v} \beta 6$ is overexpressed in associated locoregional lymph node metastases compared with background tissue and negative lymph nodes. If TBRs for involved lymph nodes are applicable, FGS positive nodes could improve overall survival [41]. In addition, future research should investigate whether adjuvant radiotherapy, as part of treatment for locally advanced and metastatic disease, is of influence on $\alpha \mathrm{v} \beta 6$ expression patterns. 
As indicated above, evaluation of $\alpha \mathrm{v} \beta 6$ as a target for FGS of vulvar (pre)malignancies was chosen based on promising (pre)clinical results in other cancer types [20]. The benefit of this is the availability of imaging agents targeting $\alpha v \beta 6$, like the recently developed linear peptide A20FMDV2 or knottin-peptide R01-MG [42,43]. For FGS application the latter peptide was conjugated to fluorescent tracer IRDye800CW to improve complete resection of patients with pancreatic ductal adenocarcinoma. In subcutaneous and orthotopic mouse pancreatic tumor models R01-MG-IRDye 800 showed specific targeting to $\alpha \mathrm{v} \beta 6$ and holds promise as a tool to recognize pancreatic cancer with FGS [42]. Another example of a fluorescent imaging agent is cRGD-ZW800-1, that binds primarily to $\alpha \mathrm{v} \beta 3$ but has also affinity for $\alpha \mathrm{v} \beta 6$. This agent is already assessed for clinical use in colorectal cancer imaging [44]. No data can be found on $\alpha \mathrm{v} \beta 3$ expression in vulvar tissue. Therefore, the potential of this imaging agent for FGS in VSCC should be further investigated.

Although this paper focused on immunohistochemical evaluation of molecular imaging targets meant for FGS, $\alpha \mathrm{v} \beta 6$ could also be used as target for imaging with PET or SPECT /CT $[45,46]$. In addition, $\alpha \mathrm{v} \beta 6$ could be used as target for different treatment modalities. It's suitability for this purposes indicated by several anticancer strategies based on $\alpha v \beta 6$ targeting, including immunoliposomes used as vectors in tumor targeted therapy [47]. Future research should focus on evaluation of $\alpha \mathrm{v} \beta 6$-targeting probes in ex-vivo models, for instance in 3D vulvar skin-tumor models, as a step towards clinical translatability [48,49]. Presuming that targets expressed on VSCC-cells are mostly unoccupied in-situ, so that an $\alpha \mathrm{v} \beta 6$-targeted FGS probe will be able to access the ligand binding site. Besides multiple deployment of this $\alpha \mathrm{v} \beta 6$ target, it would also be nice to verify in future studies if the modality FGS on itself might be useful for other vulvar diseases, as e.g., Paget disease of the vulva, which often extends beyond the visible lesion.

Next to the limited size of the cohort a limitation of this study is the pre-selection of biomarkers. The selection was based on enhanced expression of targets as described in the available literature and effectiveness of tracers against these targets obtained from studies with other tumor types $[17,18,20,22-24]$. Alternatively, an 'omics' search could be performed in combination with artificial intelligence to detect all currently (un)known targets and check their expression on vulvar healthy compared to (pre)malignant tissues. Nevertheless, promising target/tracer combinations based on 'omics' findings should still be evaluated in the clinic. Another limitation is the slight overestimation of Qupath for epithelial cells in stromal areas, which was observed in most tissue sections. As this phenomenon was equally observed in all differently selected tissue types, we assessed that it does not affect the tumor-to-background ratio substantially. It might even underestimate this ratio as almost all stromal cells stained negative. In addition, the semi-automated analysis using Qupath on small cohorts is labor intensive, even compared to visual scoring of IHC-stained sections. It is therefore desirable to further optimize this method, before testing the potential of targets for IGS application on a larger cohort of tissues. A self-learning algorithm can be drawn based on this training set for future reference. Furthermore, since this study was limited by scarcity of vulvar (pre)malignant tissues, it was not possible to define the sensitivity and specificity for IGS suitability per marker. However, this set could be used as a 'training set' for a future multicenter study wherein sufficient vulvar tissue samples can be included.

\section{Conclusions}

$\alpha v \beta 6$ is a promising target for tumor-specific (pre- and intra-operative) molecular imaging of VSCC lesions, which can be hard to distinguish from healthy tissue. For HPV-unrelated VSCCs with adjacent dVIN, that comprise the vast majority of all VSCCs, $\alpha v \beta 6$ has shown great potential for precise discrimination at the superficial tissue margins. Further research is needed to validate the use of an $\alpha \mathrm{v} \beta 6$-targeted probe for FGS of vulvar (pre)malignancies. Finally, it should be verified whether addition of this technique leads to fewer recurrences and surgery-related morbidities for VSCC patients. 
Supplementary Materials: The following are available online at https:/ / www.mdpi.com/article/ 10.3390/cancers13236006/s1, Table S1: Antigen retrieval methods applied: pepsin, trypsin and DAKO citrate buffers; Script S1: Script used for digital pathology image analysis using Qupath; Figure S1: Zoomed images of immunohistochemical control staining's of nine examined markers, Figure S2: By Qupath processed tissue sections of a patient with HPV-dependent VSCC, Figure S3: By Qupath processed tissue sections of a patient with HPV-independent VSCC with tissue transition zones, Figure S4: Comparison of MUC1, CAIX and uPAR TBRs against $\alpha v \beta 6$ TBRs for VSCC patients.

Author Contributions: Conceptualization, J.B., M.I.E.v.P. and A.L.V.; methodology, C.F.M.S.; software, B.W.H. and M.C.; validation, B.W.H., T.B., and M.C.; formal analysis, B.W.H.; investigation, B.W.H.; resources, J.B.; data curation, B.W.H.; writing-original draft preparation, B.W.H.; writingreview and editing, C.F.M.S., M.I.E.v.P. and R.R.; visualization, C.F.M.S. and B.W.H.; supervision, M.I.E.v.P. and C.F.M.S.; project administration, B.W.H.; funding acquisition, M.I.E.v.P. All authors have read and agreed to the published version of the manuscript.

Funding: This research received external funding of the 'Bontiusstichting-LUMC' for the purchase of antibodies. C.S. was in part funded by the European Commission under Marie SkłodowskaCurie Action awards, H2020-MSCA-RISE-2018, ID 777682-CANCER, H2020-MSCA-RISE 2019, ID 872860-PRISAR2, and H2020-WIDESPREAD-2018-Twinning 852985-SIMICA.

Institutional Review Board Statement: Sample collection was approved by the local ethics review board 'Medische Ethische Toetsingscommissie Leiden Den Haag Delft'-reference number B19.025.

Informed Consent Statement: Patient consent was waived as the Dutch Ethics Committee approved this research being 'not covered by the WMO (Wet Medisch-Wetenschappelijk Onderzoek) law', as we did not possess any patient-related information of the included tissues. Therefore, no informed consent was required.

Data Availability Statement: The study did not report this type of data.

Acknowledgments: We gratefully thank George Sangster, who provided medical writing services on behalf of the Centre for Human Drug Research, Leiden, The Netherlands. The authors thank Ronald Vlierberghe, Geeske Dekker-Ensink and Shadhvi Bhairosingh (LUMC department of surgery) for excellent technical assistance. A. Mazar (Monopar Therapeutics Inc., Wilmette, IL, USA) kindly provided the UPAR antibody.

Conflicts of Interest: The authors declare no conflict of interest.

\begin{abstract}
Abbreviations
avß6-integrin alphavbeta6, CAIX — carbonic anhydrase IX, CD44v6-CD44 variant 6, EGFRepidermal growth factor receptor, EpCAM - epithelial cell adhesion molecule, FR $\alpha$-folate receptor $\alpha$, MRP1-multidrug resistance-associated protein, MUC1—mucin 1, uPAR—urokinase plasminogen activator receptor.
\end{abstract}

\title{
References
}

1. Eva, L.J.; Sadler, L.; Fong, K.L.; Sahota, S.; Jones, R.W.; Bigby, S.M. Trends in HPV-dependent and HPV-independent vulvar cancers: The changing face of vulvar squamous cell carcinoma. Gynecol. Oncol. 2020, 157, 450-455. [CrossRef]

2. Tan, A.; Bieber, A.K.; Stein, J.; Pomeranz, M.K. Diagnosis and management of vulvar cancer: A review. J. Am. Acad. Dermatol. 2019, 81, 1387-1396. [CrossRef]

3. Schuurman, M.; Einden, L.V.D.; Massuger, L.; Kiemeney, L.; van der Aa, M.; de Hullu, J. Trends in incidence and survival of Dutch women with vulvar squamous cell carcinoma. Eur. J. Cancer 2013, 49, 3872-3880. [CrossRef]

4. Thuijs, N.B.; Van Beurden, M.; Bruggink, A.H.; Steenbergen, R.D.M.; Berkhof, J.; Bleeker, M.C.G. Vulvar intraepithelial neoplasia: Incidence and long-term risk of vulvar squamous cell carcinoma. Int. J. Cancer 2021, 148, 90-98. [CrossRef]

5. Hinten, F.; Molijn, A.; Eckhardt, L.; Massuger, L.; Quint, W.; Bult, P.; Bulten, J.; Melchers, W.; de Hullu, J. Vulvar cancer: Two pathways with different localization and prognosis. Gynecol. Oncol. 2018, 149, 310-317. [CrossRef] [PubMed]

6. McAlpine, J.N.; Kim, S.Y.; Akbari, A.; Eshragh, S.; Reuschenbach, M.; Doeberitz, M.V.K.; Prigge, E.S.; Jordan, S.; Singh, N.; Miller, D.M.; et al. HPV-independent Differentiated Vulvar Intraepithelial Neoplasia (dVIN) is Associated With an Aggressive Clinical Course. Int. J. Gynecol. Pathol. 2017, 36, 507-516. [CrossRef] [PubMed] 
7. Oonk, M.H.; Planchamp, F.; Baldwin, P.; Bidzinski, M.; Brännström, M.; Landoni, F.; Mahner, S.; Mahantshetty, U.; Mirza, M.; Petersen, C.; et al. European Society of Gynaecological Oncology Guidelines for the Management of Patients With Vulvar Cancer. Int. J. Gynecol. Cancer 2017, 27, 832-837. [CrossRef] [PubMed]

8. Dellinger, T.H.; Hakim, A.A.; Lee, S.J.; Wakabayashi, M.T.; Morgan, R.J.; Han, E.S. Surgical Management of Vulvar Cancer. J. Natl. Compr. Cancer Netw. 2016, 15, 121-128. [CrossRef]

9. Nooij, L.; Brand, F.; Gaarenstroom, K.; Creutzberg, C.; de Hullu, J.; van Poelgeest, M. Risk factors and treatment for recurrent vulvar squamous cell carcinoma. Crit. Rev. Oncol. 2016, 106, 1-13. [CrossRef]

10. Gaarenstroom, K.N.; Kenter, G.G.; Trimbos, J.B.; Agous, I.; Amant, F.; Peters, A.A.W.; Vergote, I. Postoperative complications after vulvectomy and inguinofemoral lymphadenectomy using separate groin incisions. Int. J. Gynecol. Cancer 2003, 13, 522-527. [CrossRef]

11. Muigai, J.; Jacob, L.; Dinas, K.; Kostev, K.; Kalder, M. Potential delay in the diagnosis of vulvar cancer and associated risk factors in women treated in German gynecological practices. Oncotarget 2018, 9, 8725-8730. [CrossRef]

12. Micheletti, L.; Preti, M.; Cintolesi, V.; Corvetto, E.; Privitera, S.; Palmese, E.; Benedetto, C. Prognostic impact of reduced tumor-free margin distance on long-term survival in FIGO stage IB/II vulvar squamous cell carcinoma. J. Gynecol. Oncol. 2018, 29 , e61. [CrossRef]

13. Nooij, L.S.; van der Slot, M.A.; Dekkers, O.M.; Stijnen, T.; Gaarenstroom, K.N.; Creutzberg, C.L.; Smit, V.T.H.B.M.; Bosse, T.; Van Poelgeest, M.I.E. Tumour-free margins in vulvar squamous cell carcinoma: Does distance really matter? Eur. J. Cancer 2016, 65, 139-149. [CrossRef]

14. Vahrmeijer, A.L.; Hutteman, M.; Van Der Vorst, J.R.; Van De Velde, C.J.H.; Frangioni, J.V. Image-guided cancer surgery using near-infrared fluorescence. Nat. Rev. Clin. Oncol. 2013, 10, 507-518. [CrossRef]

15. Rosenthal, E.L.; Warram, J.M.; de Boer, E.; Basilion, J.P.; Biel, M.A.; Bogyo, M.; Bouvet, M.; Brigman, B.E.; Colson, Y.L.; DeMeester, S.R.; et al. Successful Translation of Fluorescence Navigation During Oncologic Surgery: A Consensus Report. J. Nucl. Med. 2016, 57, 144-150. [CrossRef]

16. Boonstra, M.C.; De Geus, S.W.; Prevoo, H.A.; Hawinkels, L.; Van De Velde, C.J.; Kuppen, P.J.; Vahrmeijer, A.L.; Sier, C.F. Selecting Targets for Tumor Imaging: An Overview of Cancer-Associated Membrane Proteins. Biomarkers Cancer 2016, 8, BIC-S38542. [CrossRef] [PubMed]

17. Hernot, S.; van Manen, L.; Debie, P.; Mieog, J.S.D.; Vahrmeijer, A.L. Latest developments in molecular tracers for fluorescence image-guided cancer surgery. Lancet Oncol. 2019, 20, e354-e367. [CrossRef]

18. De Muynck, L.D.A.N.; Gaarenstroom, K.N.; Sier, C.F.M.; Van Duijvenvoorde, M.; Bosse, T.; Mieog, J.S.D.; De Kroon, C.D.; Vahrmeijer, A.L.; Peters, I.T.A. Novel Molecular Targets for Tumor-Specific Imaging of Epithelial Ovarian Cancer Metastases. Cancers 2020, 12. [CrossRef] [PubMed]

19. Hollandsworth, H.M.; Turner, M.A.; Hoffman, R.M.; Bouvet, M. A review of tumor-specific fluorescence-guided surgery for colorectal cancer. Surg. Oncol. 2021, 36, 84-90. [CrossRef]

20. Baart, V.M.; Van Duijn, C.; Van Egmond, S.L.; Dijckmeester, W.A.; Jansen, J.C.; Vahrmeijer, A.L.; Sier, C.F.M.; Cohen, D. EGFR and $\alpha v \beta 6$ as Promising Targets for Molecular Imaging of Cutaneous and Mucosal Squamous Cell Carcinoma of the Head and Neck Region. Cancers 2020, 12, 1474. [CrossRef]

21. Odenthal, J.; Rijpkema, M.; Bos, D.; Wagena, E.; Croes, H.; Grenman, R.; Boerman, O.; Takes, R.; Friedl, P. Targeting CD44v6 for fluorescence-guided surgery in head and neck squamous cell carcinoma. Sci. Rep. 2018, 8, 1-11. [CrossRef]

22. Huisman, B.; Burggraaf, J.; Vahrmeijer, A.; Schoones, J.; Rissmann, R.; Sier, C.; Van Poelgeest, M. Potential targets for tumorspecific imaging of vulvar squamous cell carcinoma: A systematic review of candidate biomarkers. Gynecol. Oncol. 2020, 156, 734-743. [CrossRef]

23. Christensen, A.; Juhl, K.; Persson, M.; Charabi, B.W.; Mortensen, J.; Kiss, K.; Lelkaitis, G.; Rubek, N.; Von Buchwald, C.; Kjær, A. uPAR-targeted optical near-infrared (NIR) fluorescence imaging and PET for image-guided surgery in head and neck cancer: Proof-of-concept in orthotopic xenograft model. Oncotarget 2016, 8, 15407-15419. [CrossRef]

24. Boonstra, M.; Van Driel, P.; Keereweer, S.; Prevoo, H.; Stammes, M.; Baart, V.; Löwik, C.; Mazar, A.; van de Velde, C.; Vahrmeijer, A.; et al. Preclinical uPAR-targeted multimodal imaging of locoregional oral cancer. Oral Oncol. 2017, 66, 1-8. [CrossRef]

25. Cheng, A.S.; Karnezis, A.N.; Jordan, S.; Singh, N.; McAlpine, J.N.; Gilks, C.B. p16 Immunostaining Allows for Accurate Subclassification of Vulvar Squamous Cell Carcinoma Into HPV-Associated and HPV-Independent Cases. Int. J. Gynecol. Pathol. 2016, 35, 385-393. [CrossRef]

26. Kortekaas, K.E.; Bastiaannet, E.; van Doorn, H.C.; de Vos van Steenwijk, P.J.; Ewing-Graham, P.C.; Creutzberg, C.L.; Akdeniz, K.; Nooij, L.S.; van der Burg, S.H.; Bosse, T.; et al. Vulvar cancer subclassification by HPV and p53 status results in three clinically distinct subtypes. Gynecol. Oncol. 2020, 159, 649-656. [CrossRef]

27. Dasgupta, S.; Ewing-Graham, P.C.; Swagemakers, S.M.; van der Spek, P.J.; van Doorn, H.C.; Hegt, V.N.; Koljenović, S.; van Kemenade, F.J. Precursor lesions of vulvar squamous cell carcinoma - histology and biomarkers: A systematic review. Crit. Rev. Oncol. 2020, 147, 102866. [CrossRef]

28. Rakislova, N.; Alemany, L.; Clavero, O.; Saco, A.; Torné, A.; Del Pino, M.; Munmany, M.; Rodrigo-Calvo, M.; Guerrero, J.; Marimon, L.; et al. p53 Immunohistochemical Patterns in HPV-Independent Squamous Cell Carcinomas of the Vulva and the Associated Skin Lesions: A Study of 779 Cases. Int. J. Mol. Sci. 2020, 21, 8091. [CrossRef] [PubMed] 
29. Bankhead, P.; Loughrey, M.B.; Fernández, J.A.; Dombrowski, Y.; McArt, D.G.; Dunne, P.D.; McQuaid, S.; Gray, R.T.; Murray, L.J.; Coleman, H.G.; et al. QuPath: Open source software for digital pathology image analysis. Sci. Rep. 2017, 7, 1-7. [CrossRef] [PubMed]

30. Berben, L.; Wildiers, H.; Marcelis, L.; Antoranz, A.; Bosisio, F.; Hatse, S.; Floris, G. Computerised scoring protocol for identification and quantification of different immune cell populations in breast tumour regions by the use of QuPath software. Histopathology 2020, 77, 79-91. [CrossRef] [PubMed]

31. Greene, C.; O’Doherty, E.; Sidi, F.A.; Bingham, V.; Fisher, N.C.; Humphries, M.P.; Craig, S.G.; Harewood, L.; McQuaid, S.; Lewis, C.; et al. The Potential of Digital Image Analysis to Determine Tumor Cell Content in Biobanked Formalin-Fixed, Paraffin-Embedded Tissue Samples. Biopreservation Biobanking 2021, 19, 324-331. [CrossRef] [PubMed]

32. Thike, A.A.; Chng, M.J.; Tan, P.H.; Fook-Chong, S. Immunohistochemical expression of hormone receptors in invasive breast carcinoma: Correlation of results of H-score with pathological parameters. Pathology 2001, 33, 21-25. [CrossRef]

33. Van Oosten, M.; Crane, L.M.; Bart, J.; van Leeuwen, F.W.; van Dam, G.M. Selecting Potential Targetable Biomarkers for Imaging Purposes in Colorectal Cancer Using TArget Selection Criteria (TASC): A Novel Target Identification Tool. Transl. Oncol. 2011, 4, 71-82. [CrossRef]

34. Hoogstins, C.E.; Weixler, B.; Boogerd, L.S.; Hoppener, D.J.; Prevoo, H.A.; Sier, C.; Burger, J.W.; Verhoef, C.; Bhairosingh, S.; Sarasqueta, A.F.; et al. In Search for Optimal Targets for Intraoperative Fluorescence Imaging of Peritoneal Metastasis From Colorectal Cancer. Biomarkers Cancer 2017, 9, 1179299-1772825. [CrossRef]

35. Aleksandrov, A.; Meshulam, M.; Smith, A.V.; Chauvet, P.; Canis, M.; Bourdel, N. Fluorescence-guided management of deep endometriosis. Fertil. Steril. 2020, 114, 1116-1118. [CrossRef]

36. Chantima, W.; Thepthai, C.; Cheunsuchon, P.; Dharakul, T. EpCAM expression in squamous cell carcinoma of the uterine cervix detected by monoclonal antibody to the membrane-proximal part of EpCAM. BMC Cancer 2017, 17, 811. [CrossRef]

37. Bolognia, J.L. Aging skin. Am. J. Med. 1995, 98, S99-S103. [CrossRef]

38. Koivisto, L.; Bi, J.; Häkkinen, L.; Larjava, H. Integrin $\alpha v \beta 6$ : Structure, function and role in health and disease. Int. J. Biochem. Cell Biol. 2018, 99, 186-196. [CrossRef]

39. Desgrosellier, J.S.; Cheresh, D.A. Integrins in cancer: Biological implications and therapeutic opportunities. Nat. Rev. Cancer 2010, 10, 9-22. [CrossRef]

40. Binmadi, N.; Elsissi, A.; Elsissi, N. Expression of cell adhesion molecule CD44 in mucoepidermoid carcinoma and its association with the tumor behavior. Head Face Med. 2016, 12, 1-5. [CrossRef] [PubMed]

41. Chen, J.; Ln, H. A Review of Prognostic Factors in Squamous Cell Carcinoma of the Vulva: Evidence from the Last Decade. Semin. Diagn. Pathol. 2020. [CrossRef] [PubMed]

42. Tummers, W.S.; Kimura, R.H.; Abou-Elkacem, L.; Beinat, C.; Vahrmeijer, A.L.; Swijnenburg, R.-J.; Willmann, J.K.; Gambhir, S.S. Development and Preclinical Validation of a Cysteine Knottin Peptide Targeting Integrin $\alpha$ v $\beta 6$ for Near-infrared Fluorescentguided Surgery in Pancreatic Cancer. Clin. Cancer Res. 2018, 24, 1667-1676. [CrossRef] [PubMed]

43. Hausner, S.H.; DiCara, D.; Marik, J.; Marshall, J.F.; Sutcliffe, J.L. Use of a peptide derived from foot-and-mouth disease virus for the noninvasive imaging of human Cancer: Generation and evaluation of 4-[18F]fluorobenzoyl A20FMDV2 for in vivo imaging of integrin $\alpha \mathrm{v} \beta 6$ expression with positron emission tomography. Cancer Res. 2007, 67, 7833-7840. [CrossRef]

44. De Valk, K.S.; Deken, M.M.; Handgraaf, H.J.M.; Bhairosingh, S.S.; Bijlstra, O.D.; Van Esdonk, M.J.; Van Scheltinga, A.G.T.; Valentijn, A.R.P.; March, T.L.; Vuijk, J.; et al. First-in-Human Assessment of cRGD-ZW800-1, a Zwitterionic, Integrin-Targeted, Near-Infrared Fluorescent Peptide in Colon Carcinoma. Clin. Cancer Res. 2020, 26, 3990-3998. [CrossRef]

45. Saleem, A.; Helo, Y.; Win, Z.; Dale, R.; Cook, J.; Searle, G.E.; Wells, P. Integrin $\alpha v \beta 6$ Positron Emission Tomography Imaging in Lung Cancer Patients Treated With Pulmonary Radiation Therapy. Int. J. Radiat. Oncol. 2020, 107, 370-376. [CrossRef]

46. Sachindra, S.; Hellberg, T.; Exner, S.; Prasad, S.; Beindorff, N.; Rogalla, S.; Kimura, R.; Gambhir, S.S.; Wiedenmann, B.; Grötzinger, C. SPECT/CT Imaging, Biodistribution and Radiation Dosimetry of a 177Lu-DOTA-Integrin $\alpha$ v 36 Cystine Knot Peptide in a Pancreatic Cancer Xenograft Model. Front. Oncol. 2021, 11. [CrossRef]

47. Liang, B.; Shahbaz, M.; Wang, Y.; Gao, H.; Fang, R.; Niu, Z.; Liu, S.; Wang, B.; Sun, Q.; Niu, W.; et al. Integrinß6-Targeted Immunoliposomes Mediate Tumor-Specific Drug Delivery and Enhance Therapeutic Efficacy in Colon Carcinoma. Clin. Cancer Res. 2015, 21, 1183-1195. [CrossRef] [PubMed]

48. Niehues, H.; Bouwstra, J.A.; El Ghalbzouri, A.; Brandner, J.M.; Zeeuwen, P.L.J.M.; Van Den Bogaard, E.H. 3D skin models for 3R research: The potential of 3D reconstructed skin models to study skin barrier function. Exp. Dermatol. 2018, $27,501-511$. [CrossRef] [PubMed]

49. Mathes, S.H.; Ruffner, H.; Graf-Hausner, U. The use of skin models in drug development. Adv. Drug Deliv. Rev. 2014, 69-70, 81-102. [CrossRef] 